\title{
Causes of Death in an Acute Psychiatric Inpatient Unit of a Portuguese General Hospital
}

\section{Causas de Morte numa Unidade de Internamento de Agudos de Psiquiatria de um Hospital Geral Português}

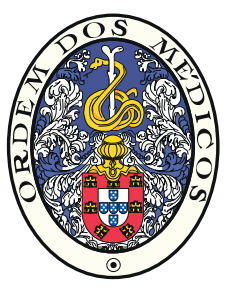

\author{
Sofia BARBOSA $\triangle^{1}$, Márcia SEQUEIRA ${ }^{1}$, Sara CASTRO ${ }^{1}$, Rita MANSO ${ }^{2}$, Catarina Klut CÂMARA ${ }^{1}$, Bruno TRANCAS $^{1,3}$, \\ Nuno BORJA-SANTOS ${ }^{1}$, Teresa MAIA ${ }^{1}$ \\ Acta Med Port 2016 Jul-Aug;29(7-8):468-475 - http://dx.doi.org/10.20344/amp.6905
}

\section{ABSTRACT}

Introduction: Psychiatric patients are at increased risk of death from a number of natural and unnatural causes. This study examines the mortality causes of all psychiatric inpatients of an acute psychiatric unit at a general hospital in Portugal for sixteen years (1998 to 2013).

Material and Methods: Twenty-one inpatients died at the inpatient unit between 1998 and 2013 (average 1.3 per year). A retrospective study through case-file review was carried to collect demographic characteristics, medical and psychiatry diagnosis. Patients transferred to other wards during their admission were not included.

Results: Circulatory system diseases were the most prevalent causes of death, occurring in $2 / 3$ of patients and include pulmonary embolism $(n=6)$, acute stroke $(n=3)$, cardiac arrhythmia $(n=2)$, acute myocardial infarction $(n=1)$, abdominal aortic aneurysm rupture $(n=1)$ and heart failure $(n=1)$. Two patients died with pneumonia and in four cases the cause of death was undetermined. Only one case of suicide was registered.

Discussion: Circulatory conditions were the most frequent causes of death in our inpatient unit. Albeit a relatively rare event, inpatient suicide does occur and, in addition to its complex consequences on staff, family and patients should remain a focus for continued prevention.

Conclusion: Mortality studies are important for determining quality of health care and to create recommendations for preventive measures.

Keywords: Cause of Death; Hospital Mortality; Mental Disorders/mortality; Portugal; Psychiatric Department, Hospital.

\section{RESUMO}

Introdução: Os doentes afectos de patologia psiquiátrica apresentam maior risco de morte, tanto por causas naturais como não naturais. Este estudo avalia as causas de morte de todos os doentes de uma unidade de internamento de agudos de Psiquiatria num hospital geral em Portugal, ao longo de dezasseis anos (de 1998 a 2013).

Material e Métodos: Vinte e um doentes morreram na unidade de internamento de doentes agudos entre 1998 e 2013 (média 1,3 por ano). As características demográficas, os diagnósticos médicos e psiquiátricos foram recolhidos através de um estudo retrospectivo que consistiu na análise dos processos clínicos da amostra selecionada. Os doentes transferidos para outras enfermarias durante o internamento não foram incluídos no estudo.

Resultados: As doenças do sistema circulatório foram as causas de morte mais prevalentes, ocorrendo em $2 / 3$ dos doentes, incluindo embolismo pulmonar $(n=6)$, acidente vascular cerebral $(n=3)$, arritmia cardíaca $(n=2)$, enfarte agudo do miocárdio $(n=1)$, rutura de aneurisma da aorta abdominal $(n=1)$ e insuficiência cardíaca $(n=1)$. Dois doentes morreram de pneumonia e em quatro casos a causa de morte foi indeterminada. Apenas um caso de suicídio foi registado.

Discussão: As doenças do aparelho circulatório foram as causas de morte mais frequentes nesta unidade de agudos. O suicídio em doentes internados, apesar de constituir um evento raro, é uma realidade que comporta consequências complexas para os profissionais de saúde, familiares e restantes doentes, devendo permanecer como foco de prevenção continuada.

Conclusão: Os estudos de mortalidade são importantes para determinar a qualidade dos cuidados de saúde e criar recomendações para medidas preventivas.

Palavras-chave: Causas de Morte; Mortalidade Hospitalar; Perturbações Mentais/mortalidade; Portugal; Serviço Hospitalar de Psiquiatria.

\section{INTRODUCTION}

Evidence has consistently shown that patients with mental illness have greater health morbidity and mortality compared to the general population. ${ }^{1}$ In addition, it has also been observed that 'all cause' mortality is higher in psychiatric populations - in comparison with the general public or other patient groups - much of it related to 'unnatural causes', such as accidents or suicides. ${ }^{2}$ The latter, irrespective of its general low frequency, is regarded as a

particularly relevant risk in this population ${ }^{3-7}$ and the rate of inpatient suicide has been reported to be between $0.1 \%$ and $0.4 \%$ of all psychiatric admissions ${ }^{3,8}$ In a study about inpatients' suicide five to $6.5 \%$ of suicides were committed in the hospital: $3 \%$ to $5.5 \%$ occurred in psychiatric hospitals and about $2 \%$ in general hospitals. ${ }^{9}$

Standardized mortality ratios for natural deaths, however, are also raised in many psychiatric populations. ${ }^{2}$

1. Department of Psychiatry. Hospital Prof. Doutor Fernando Fonseca. Amadora. Portugal.

2. Department of Pathology and Anatomical Sciences. Hospital Prof. Doutor Fernando Fonseca. Amadora. Portugal.

3. Department of Mental Health. NOVA Medical School. Universidade Nova de Lisboa. Lisbon. Portugal.

$\square$ Autor correspondente: Sofia Barbosa. sofiabarbosa.fcml@gmail.com

Recebido: 11 de agosto de 2015 - Aceite: 16 de maio de 2016 | Copyright @ Ordem dos Médicos 2016 
Studies that were published prior to the deinstitutionalization of psychiatric patients have limited current applicability. This rationale stands upon the assumption that deep changes have taken place in mental health care, such as the move toward community care, the availability of drugs with different side effects profile and greater involvement of primary care physicians in the care of chronic psychiatric patients. $^{2}$

The older psychiatric patients with comorbidity continue to place costly demands for specialized services of acute medical care and hospice management. ${ }^{10-14}$ These demands are shifting the focus of the public hospital in a new direction: how to deal with increasing medical problems of older adults with psychiatric diagnoses. ${ }^{13}$

Explanations for the higher morbidity and mortality in mental illness include cardiovascular and respiratory problems and not only increased suicide risk. ${ }^{1}$ Many factors have been implicated and include adverse effects of medications (such as dyslipidemia, metabolic syndrome, impaired glucose tolerance and diabetes), underlying physical illness and inability to access general healthcare, and also lifestyle factors (substance use, including alcohol and tobacco, sedentary lifestyle, poor dietary habits and obesity)..$^{1,2,15}$

The extent of morbidity and mortality in mental illness is widely acknowledged, particularly in affective disorders, schizophrenia and also in eating disorders. ${ }^{1,2,16,17}$ The prevalence of diabetes, stroke and myocardial infarction is higher in patients suffering from depression. ${ }^{1,16}$ Regarding patients with schizophrenia, several studies report increased rates of diabetes, obesity and cardiovascular disease,,$^{1,18-21}$ including myocardial infarction, when compared to the general population. 2,22,23 Interestingly, rates of cancer in schizophrenia do not appear to be raised. ${ }^{2}$ In fact, cancer may occur less frequently than in general population ${ }^{18}$ and most of the studies that found it speculated on genetic factors that lead to schizophrenia on the one hand but protect from cancer on the other. ${ }^{18}$ Other hypotheses postulated that certain antipsychotic drugs protect against tumors, ${ }^{24}$ and that environmental factors such as frequent hospitalizations may be responsible for the low comorbidity. ${ }^{25-27}$ However, even after many years of research this epidemiological doubt remains unsolved and requires further studies.

Despite the high morbidity risk, health care seeking behavior is also an aspect worth discussing. Certain psychiatric symptoms may render patients less inclined to discuss physical problems and to seek help from a primary care physician, namely delusions, cognitive deficits, reduced pain sensitivity (whether endophenotype-like ${ }^{28}$ or induced by antipsychotic medication) and even deficient social skills. Poor patient-doctor communication or lack of awareness from physicians (including psychiatrists) may contribute to dismiss or misconstrue physical symptoms by treating them as psychosomatic or even psychotic, sometimes delaying diagnosis and treatment. ${ }^{1}$

High mortality rates among individuals with mental illness have been reported in various studies, but little focus has been placed on the cause of death. ${ }^{29,30}$ Data regarding mortality during inpatient stay in psychiatric units is still scarce, particularly concerning general hospitals. We propose to analyze and discuss the causes of death in an acute psychiatric inpatient unit in a general hospital. We believe that mortality studies are important for determining quality of health care and to create recommendations for preventive measures. In psychiatric epidemiology, death is an important data point, which can be used more precisely for both research and service planning. ${ }^{29,30}$ Rethinking medical risks, morbidity and mortality of patients with mental disorders may allow us to develop strategies that decrease fragmentation of general and mental health care systems and improve the quality of care.

\section{MATERIAL AND METHODS}

This study was conducted in the acute inpatient unit of a community-based psychiatric service, integrated in a public general hospital. The Fernando Fonseca Hospital (HFF) was created in 1998, and offers comprehensive mental health care to the municipality of Amadora and three parishes of Sintra, in Portugal. It serves a highly urban and multiethnic population of over 300,000 people in the suburbs of Lisbon, Portugal. Over $10 \%$ of residents are legal immigrants (4\% from Cape Verde, 2\% from Brazil, $1 \%$ from Guinea-Bissau, $1 \%$ from Angola, 1\% from other African countries, and $1 \%$ from other European countries). ${ }^{31}$ An undetermined number of illegal immigrants also use the psychiatric service. ${ }^{31}$ The inpatient unit is a 29-bed acute psychiatric ward, located in the general hospital, and provides standard psychiatric inpatient care that includes clinical evaluation, psychopharmacological treatment, nursing care, and occupational therapy. It has an annual discharge rate ranging from 381 to 621 (average of $486 \pm$ $70.9)^{32}$ and patients are then followed-up at the community level of care. ${ }^{31}$ Data was hand searched and collected retrospectively through case file review (hardcopy) of the inpatients that died in this acute psychiatric inpatient unit, between 1998 and 2013. Patients that were transferred to other medical wards during their admission were not included in this analysis since their clinical information was unavailable. Case file notes, death certificates, autopsy and pathological anatomy data were reviewed to examine demographic data, psychiatric diagnosis, inpatient length of stay, cause of death and medical conditions. In order to access this data, approval was obtained by the hospital's ethics committee and anonymity was assured. The International Classification of Diseases (ICD-10) was used in order to classify all the diseases referred during this text.

\section{RESULTS \\ Demographic characterization}

During this 16-year period (January 1998 to December 2013), there was a total of 7,772 psychiatric inpatient admissions, out of which 21 patients died during their inpatient stay (average 1.3 deaths per year).

Table 1 outlines the socio-demographic profile of the 
Table 1 - Demographic features of the inpatient sample

\begin{tabular}{|c|c|c|c|c|}
\hline \multirow[t]{2}{*}{ Demographic features } & \multicolumn{2}{|c|}{$\begin{array}{c}\text { Deceased patients } \\
\quad(1998-2013)\end{array}$} & \multicolumn{2}{|c|}{$\begin{array}{c}\text { Ward population } \\
(1998-2013)\end{array}$} \\
\hline & $\mathbf{n}$ & $\%$ & $\mathbf{n}$ & $\%$ \\
\hline \multicolumn{5}{|l|}{ Gender } \\
\hline Male & 12 & 57.1 & 2,604 & 33.50 \\
\hline Female & 9 & 42.9 & 5,168 & 66.50 \\
\hline \multicolumn{5}{|l|}{ Age } \\
\hline 18 to 65 years & 16 & 76.20 & 6,988 & 89.91 \\
\hline \multirow[t]{2}{*}{ over 65 years } & 5 & 23.80 & 784 & 10.09 \\
\hline & Mean & SD & Mean & SD \\
\hline Age & 50.81 & 19.18 & 40.7 & 16.0 \\
\hline Age of male patients & 51 & 21.07 & 42.0 & 16.1 \\
\hline Age of female patients & 50.56 & 17.59 & 40.0 & 15.9 \\
\hline
\end{tabular}

patients admitted to the ward from 1998 to 2013. Of the deceased patients, twelve $(57.1 \%)$ were male. Most patients belonged to the age group of $41-60$ years $(n=7 ; 33.3 \%)$; followed by the age group of $21-40$ years $(n=6 ; 28.6 \%)$ and five patients belonged to the age group of $61-80$ years (23.8\%). Only two patients were 80 years or above $(9.52 \%)$ and one with less than or 20 years $(4.76 \%)$.

The average age of the patients at the time of death was 50.81 ( \pm 19.18 ) and their age ranged from 20 years to 89 years. Most were single $(n=7 ; 33.3 \%)$ or separated/divorced ( $n=10 ; 47.6 \%$ ) and most of them were professionally inactive (retired or unemployed) $(n=12 ; 57.1 \%)$.

Two patients $(9.5 \%)$ had been admitted less than 24 hours before death (i.e. they were admitted and died on the same day); 10 (47.6\%) of them stayed less than a week and $11(52.4 \%)$ more than one week. Only one patient $(4.8 \%)$ stayed more than 2 months (64 days). The average length of stay was 10.29 days ( \pm 13.12 ) and the mode was 3 days.

\section{Psychiatric characterization}

Table 2 shows the psychiatric characteristics of the sample, including diagnosis and psychotropic drug treatment.

Among these patients, psychomotor agitation was the main cause of admission ( $n=12 ; 57.14 \%$ ). Ten patients $(47.62 \%)$ were diagnosed with a mood disorder (F30-F39) and five $(23.81 \%)$ had a diagnosis of schizophrenia (F20). The remaining patients had been diagnosed with delirium (F05) ( $\mathrm{n}=2 ; 9.52 \%$ ), unspecified non-organic psychosis (F29) ( $\mathrm{n}=2 ; 9.52 \%)$, organic mental disorder (F00-F09) ( $\mathrm{n}$ $=1 ; 4.76 \%)$ and alcohol related mental disorder $(\mathrm{F} 10)(\mathrm{n}=$ $1 ; 4.76 \%)$.

Seven patients (33.33\%) had been admitted compulsively (i.e. under the Portuguese mental health act). ${ }^{33}$

The majority of the patients ( $n=20 ; 95.2 \%$ ) had received antipsychotic drugs during their stay. Out of the five patients $(23.81 \%)$ that were mechanically restrained, two had received prophylactic anticoagulation.

\section{Cause of death and medical conditions}

Table 3 shows the cause of death and also the documented physical co-morbidities.

All but one of the patients $(n=20)$ died from natural causes, with nearly three quarters ( $n=15 ; 71.43 \%$ ) having been submitted to cardiopulmonary resuscitation.

The leading causes of death were diseases of the circulatory system ( $n=14 ; 66.66 \%$ ), mainly pulmonary embolism (I26) ( $n=6 ; 28.57 \%$ ) and stroke (I64) ( $n=3$; $14.29 \%)$. Two patients (9.52\%) died with cardiac arrhythmia (149.9), one patient $(4.76 \%)$ with acute myocardial infarction (I21), one patient $(4.76 \%)$ with abdominal aortic aneurysm rupture (I71.3) and one (4.76\%) with heart failure (I50). No patient died with myocarditis. Regarding diseases of the respiratory system $(n=2 ; 9.52 \%)$, both patients deceased from pneumonia (J18). One patient $(4.76 \%)$ committed suicide (by hanging). In four patients $(19.05 \%)$ the cause of death was undetermined.

Sixty-six percent $(n=14)$ of the patients were subjected to an autopsy. Of these, the post-mortem macroscopic and histological examination could not establish a precise etiology in three patients $(14.29 \%)$. One of these three patients had a pulmonary edema that probably was related to the cause of death and a second patient was found to have a cerebral edema that comprised the amygdalae. The third had a lymphocytic thyroiditis and possible structural abnormality of the heart but we could not find any association between these findings and the cause of death.

In $13(61.90 \%)$ patients there was a history of physical co-morbidity upon admission and 10 (76.92\%) received treatment for this medical condition. Cardiovascular disorders ( $n=9 ; 42.86 \%$ ) accounted for the majority of these somatic illnesses.

\section{DISCUSSION}

To the best of our knowledge, this is the first paper to analyze mortality causes in an acute psychiatric inpatient unit of a Portuguese general hospital. However, there is a study conducted in 1992 analyzing the death cause of psychiatric patients from Montijo and Alcochete (Portugal) 
between 1988 and 1991, but it only included outpatients. ${ }^{34}$

Although our general ward population was largely female ( $n=5,168 ; 66.50 \%)$, the mortality was higher among men $(57.1 \%)$ and these findings are consistent with earlier studies. ${ }^{35,36}$

The average age of death was 50.81 ( \pm 19.18$)$, which is higher than the average age of the total ward population $(40.7 \pm 16.0)$ and in the majority of cases it occurred in the age group of 41 - 60 years old (33.3\%).

Almost all patients $(n=20)$ deceased from natural causes and only one patient $(4.76 \%)$ died from unnatural cause, suicide by hanging, an infrequent occurrence also described in other data. ${ }^{35,37,38}$ The patient who committed suicide was a 29 year-old man with treatment refractory schizophrenia, diagnosed since he was 25 years old. According to previous research, one independent predictor

Table 2 - Psychiatric features of the deceased patients, including diagnosis and psychotropic drug treatment

\begin{tabular}{|c|c|c|}
\hline Length of stay & Mean & SD \\
\hline Average (days) & 10.29 & 13.12 \\
\hline Mode (days) & \multicolumn{2}{|c|}{3} \\
\hline Psychiatric diagnosis & $\mathbf{n}$ & $\%$ \\
\hline Schizophrenia (F20) & 5 & 23.81 \\
\hline Unspecified non-organic psychosis (F29) & 2 & 9.52 \\
\hline Mood disorder (F30 - F39) & 10 & 47.62 \\
\hline Bipolar disorder (F31) & 7 & 33.33 \\
\hline Manic episode with psychotic symptoms (F31.1) & 5 & 23.81 \\
\hline Mixed episode (F31.6) & 2 & 9.52 \\
\hline Depressive disorder (F32) & 3 & 14.29 \\
\hline Organic mental disorder (F00 - F09) & 3 & 14.29 \\
\hline Delirium (F05) & 2 & 9.52 \\
\hline Organic mental disorders associated with physical disorders (F06) & 1 & 4.76 \\
\hline Alcohol related mental disorder (F10) & 1 & 4.76 \\
\hline Compulsive (i.e. under mental health act) & 7 & 33.33 \\
\hline Global domain invoked as the main cause for admission & $\mathbf{n}$ & $\%$ \\
\hline Psychomotor agitation & 12 & 57.14 \\
\hline Mood & 2 & 9.52 \\
\hline Delusion & 2 & 9.52 \\
\hline Other & 5 & 23.81 \\
\hline Drug treatment at the ward & $\mathbf{n}$ & $\%$ \\
\hline Antipsychotics* & 20 & 95.2 \\
\hline First generation antipsychotics & 17 & 80.95 \\
\hline Haloperidol & 12 & 57.14 \\
\hline Levopromazine & 1 & 4.76 \\
\hline Chlorpromazine & 3 & 14.29 \\
\hline Thioridazine & 1 & 4.76 \\
\hline Second generation antipsychotics & 11 & 52.38 \\
\hline Clozapine & 1 & 4.76 \\
\hline Olanzapine & 6 & 28.57 \\
\hline Quetiapine & 1 & 4.76 \\
\hline Risperidone & 3 & 14.29 \\
\hline Antipsychotic polytherapy & 3 & 14.29 \\
\hline Mood stabilizers & 6 & 28.57 \\
\hline Benzodiazepines & 20 & 95.24 \\
\hline Antidepressants & 2 & 9.52 \\
\hline Physical immobilization / restraint & 5 & 23.81 \\
\hline Anticoagulant prophylaxis & 4 & 19.05 \\
\hline
\end{tabular}

${ }^{*}$ Average chlorpromazine equivalent per patient: $615.47 \pm 525.79 \mathrm{mg} /$ day 
Table 3 - Cause of death and medical conditions in psychiatric inpatients

\begin{tabular}{|c|c|c|}
\hline Cause of death in psychiatric inpatients* & $\mathbf{n}$ & $\%$ \\
\hline Diseases of the Circulatory system (100 - 199) & 14 & 66.66 \\
\hline Pulmonary embolism (I26) & 6 & 28.57 \\
\hline Stroke (164) & 3 & 14.29 \\
\hline Acute myocardial infarction (I25) & 1 & 4.76 \\
\hline Abdominal aortic aneurysm ruptured (171.3) & 1 & 4.76 \\
\hline Heart failure (I50) & 1 & 4.76 \\
\hline Cardiac arrhythmia (149.9) & 2 & 9.52 \\
\hline Diseases of the respiratory system (J00 - J99) & 2 & 9.52 \\
\hline Pneumonia, organism unspecified (J18) & 2 & 9.52 \\
\hline Intentional self-harm (X60 - X84) & 1 & 4.76 \\
\hline Intentional self-harm by hanging, strangulation and suffocation (X70) & 1 & 4.76 \\
\hline Unexplained & 4 & 19.05 \\
\hline Autopsy & 14 & 66.67 \\
\hline Cardiopulmonary resuscitation & 15 & 71.43 \\
\hline Documented medical comorbidity & 13 & 61.9 \\
\hline None & 8 & 38.1 \\
\hline Endocrine and metabolic system & 2 & 9.52 \\
\hline Respiratory system & 0 & 0 \\
\hline Infectious diseases & 2 & 9.52 \\
\hline Digestive system & 1 & 4.76 \\
\hline Genitourinary system & 2 & 9.52 \\
\hline Neoplasic disease & 2 & 9.52 \\
\hline Neurological disorders & 2 & 9.52 \\
\hline Cardiovascular system & 9 & 42.86 \\
\hline Treatment for medical condition & 10 & 76.92 \\
\hline
\end{tabular}

* Causes of death according to International Classification of Diseases, $10^{\text {th }}$ revision (ICD-10)

of inpatient suicide is being male, ${ }^{6}$ and in a case control study of 92 cases of inpatient suicides, the majority (around $70 \%$ ) also suffered from schizophrenia. ${ }^{3,8}$ Many studies showed that suicide risk is also greater in the earlier course of the admission: suicide usually occurred within the first month of admission ${ }^{8}$ and nearly a quarter of suicides took place within the first week. ${ }^{6,39}$ The total duration of psychiatric illness also appeared to be shorter for suicide cases than controls, which draws attention to the management of the first episodes of illness. Our patient, however, had had multiple previous admissions and committed suicide 64 days after admission. Besides his gender and diagnosis, other suicide risk factors were also present, namely a previous history of deliberate self-harm and suicide attempt as his reason for admission to the inpatient unit. ${ }^{8}$ This underscores the importance of continuous assessment of suicide risk in all inpatients and concern for the safety of the Inpatient Unit's facilities. After this unfortunate episode some vulnerabilities were identified and corrected.

The number of excess deaths from natural causes is in line with previous studies. ${ }^{37,40,41}$ Most patients (61.9\%) were diagnosed with a medical illness prior to death, which is similar to earlier study findings, ${ }^{42}$ and this fact underlines the need for general health interventions for this vulnerable group.

Additionally, we observed that a significant number of patients who died did so within a relatively short time after their hospitalization, which is also consistent with other studies. ${ }^{29,42}$ In our series, $46.7 \%$ of the patients who deceased had been admitted for less than a week. It is also possible that acute medical conditions, which accounted for their death early in the course of the admission, could have contributed to psychiatric symptoms that prompted the admission in the psychiatric ward. All but one of the patients that died in the first week of admission had a known previous psychiatric diagnosis (mostly schizophrenia - F20 - and bipolar disorder - F31). Although it is possible that acute psychiatric patients might have increased difficulties in expressing their physical complaints effectively (either because they explain them as integrating a delusion or perhaps they have more difficulty in interpreting them), the cornerstone of quality care provision remains on the physician. It is the task of the attending psychiatrist, in collaboration with other specialties, to see beyond the psychiatric presentation and identify other possible medical problems and prevent misdiagnosis. We believe that careful training of both general physicians and psychiatrists may minimize these difficulties and allow a better health 
orientation.

Regarding psychiatric diagnosis, the majority were diagnosed with a mood disorder (47.62\%) followed by schizophrenia (23.81\%). The psychiatric diagnostic distribution among the patients who died at our ward is globally similar to those reported in earlier studies, however, being the two most common groups of psychiatric diseases reported, ${ }^{17,29,42,43}$ affective disorders were more prevalent than schizophrenia, unlike the majority of studies. ${ }^{29,42}$ In other previous studies,,$^{17,29,42,43}$ the most prevalent diagnoses - other than substance use disorders - were schizophrenia and schizoaffective disorders followed by bipolar disorder and major depressive disorder. In all studies, we found greater mortality rates and a shorter life-expectancy for patients with schizophrenia compared to patients with bipolar disease. The fact that most of the patients that deceased in our ward had mood disorders is most likely related to its higher frequency in the admitted population ${ }^{32}$ therefore outweighing the increased risk documented for patients with schizophrenia. Furthermore, most of these studies ${ }^{43,44}$ were conducted in long stay inpatients' wards, where, typically, prevalence of patients with schizophrenia is superior to patients with affective disorders, when compared to acute inpatient units.

Among the causes of death, the leading ones were circulatory system disorders $(66.66 \%)$, mainly pulmonary embolism (28.57\%) and stroke (14.29\%). This is consistent with some studies ${ }^{35}$ where cardiovascular disorders constitute the commonest cause of death..$^{29,42,43}$ On the other hand, several previous studies have reported respiratory problems as one of the main causes for increased mortality in patients with mental illness. ${ }^{10,45}$ One possible reason could be heavy smoking, which is a very common cooccurrence, although we cannot clearly assume this by the limited information of comorbid substance abuse or smoking habits that we could collect from our patient files. We also supported earlier findings that cardiovascular disease was among the leading causes of death in this population and many reasons have been postulated as to the etiology of these results. For instance, reduced physical activity, the increased prevalence of smoking, increased substance use, use of some classes of drugs and inadequate social support systems all are likely to contribute to the development of hypertension, diabetes mellitus, infections, COPD (chronic obstructive pulmonary disease), heart disease, and injuries. ${ }^{29}$ In fact, the risk of deep venous thrombosis, leading to pulmonary embolism, is increased in patients treated with antipsychotic drugs, ${ }^{46}$ which is consistent with our findings.

Prospective studies have identified bradycinetic dysphagia secondary to neuroleptic-induced extrapyramidal syndrome ${ }^{47}$ and fast-eating syndrome ${ }^{48}$ as the most common causes of life-threatening choking episodes. ${ }^{45}$ Moreover, it appears that the increase in saliva production with some antipsychotic drugs (namely clozapine, which was not the case) may increase the risk for aspiration pneumonia, especially for those who also experience swallowing difficulties. ${ }^{48}$ Sialorrhea, esophageal hypomotility and sedation could, in certain individuals, lead to aspiration pneumonia. ${ }^{49,50}$ These phenomena may have been at the origin of the aspiration pneumonia described in one of our patients.

Another factor to bear in mind is the medication-induced weight gain, namely the metabolic effects of secondgeneration antipsychotic medications. A 2004 Consensus Statement by the American Diabetes Association, the American Psychiatric Association, and others concerning second-generation antipsychotic use and obesity, diabetes, and high cholesterol prompted guidance to physicians to carefully evaluate and monitor patients taking these medications. ${ }^{51}$ Recent mortality warnings from the Food and Drug Administration on the off-label use of second-generation antipsychotics also increases concern and enhances the need for a more comprehensive study of medicationinduced side effects. ${ }^{35}$ In our series, eleven patients $(52.38 \%)$ were taking second-generation antipsychotics, three of them receiving more than one antipsychotic. Another mechanism by which antipsychotics may cause sudden death is by cardiac arrhythmias, ${ }^{15}$ because they are known to disturb normal cardiac electrophysiology. In our sample, two patients $(9.52 \%)$ died with cardiac arrhythmia and both had more than 65 years. One patient, whose death cause was not possible to determine, had a structural cardiac abnormality reported on histological examination, which might have been be compatible with a heart dysfunction.

Some methodological issues do require attention regarding our study. We used retrospective case file and autopsy reports (macroscopic and histological examination) review to determine the cause of death in the 21 patients that deceased in the ward during the studied time-frame (1998 - 2013). This approach allowed for the identification and analysis of their demographic, medical and psychiatric characteristics. However, some data was lacking regarding pre-mortem assessment, such as information regarding the presence of some risk factors, toxicological habits and metabolic profile. Despite generally adequate investigation, a definite cause of death was found to be missing in four cases. In addition, we need to highlight the low number of patients included in our sample, which reflect a relatively low mortality rate in our unit. Nevertheless, we believe that the main findings from this study are not affected by the number of patients analyzed, such as the role of other medical problems in the mortality of psychiatric patients and the need for the health care professionals to be more aware of these findings and improve medical screening and treatment of psychiatric patients.

\section{CONCLUSION}

General medical illnesses are the most prevalent causes of death in psychiatric inpatients. The establishment of a comprehensive system of treating mental illness that encompasses regular physical health monitoring is necessary in order to provide a holistic approach to psychiatric patients that may improve patient outcomes. 
In light of the large-scale reduction of inpatient psychiatric beds and service redesign, the majority of psychiatric care is currently community-based. Therefore, community mental health and psychiatric outpatient teams need to work collaboratively with primary care, in order to assure adequate physical health care to psychiatric patients. ${ }^{1}$

Programs to improve the physical health of psychiatric patients are essential and have been shown to be effective. ${ }^{2}$ Good physical health status is a realistic goal in people with mental illness, and this goal should be embraced by all health professionals who provide their care in inpatients units. $^{2}$

Regarding suicide, precautions to reduce risk are possible and should be actively addressed. Accurately predicting which individual will commit suicide, however, remains a difficult task. ${ }^{3}$ General service-wide strategies and regular staff training, as well as establishing a low threshold for active measures in suicide risk assessment (including eliminating every possible lethal devices) would enable a more effective prevention.

Health care professionals need to be more aware of psychiatric patient's comorbid illnesses, in order to improve their medical screening and treatment. ${ }^{1}$ Psychiatrists need to keep up to date regarding most common physical health problems. Specifically, psychiatrists working at inpatient wards need to maintain high proficiency to recognize and

\section{REFERENCES}

1. Latoo J, Mistry M, Dunne FJ. Physical morbidity and mortality in people with mental illness. BJMP. 2013;6:a621.

2. Osborn DP. The poor physical health of people with mental illness. West J Med. 2001;175: 329-32.

3. Combs H, Romm S. Psychiatric inpatient suicide: a literature review. Prim Psychiatry. 2007;14:67-74.

4. Cassells C, Paterson B, Dowding D, Morrison R. Long and short-term risk factors in the prediction of inpatient suicide: review of the literature. Crisis. 2005;26:53-63.

5. Appleby L. Suicide in psychiatric patients: risk and prevention. $\mathrm{Br} \mathrm{J}$ Psychiatry. 1992;161:749-58.

6. Hunt IM, Kapur N, Webb R, Robinson J, Burns J, Turnbull P, et al. Suicide in current psychiatric in-patients: a case-control study The National Confidential Inquiry into Suicide and Homicide. Psychol Med. 2007:37:831-7.

7. Proulx F, Lesage AD, Grunberg F. One hundred in-patient suicides. Br J Psychiatry. 1997;171:247-50.

8. Dong JY, Ho TP, Kan CK. A case-control study of 92 cases of in-patient suicides. J Affect Disord. 2005;87:91-9.

9. Martelli C, Awad H, Hardy P. In-patients suicide: epidemiology and prevention. Encephale. 2010;36:D83-91.

10. Kamara SG, Peterson PD, Dennis JL. Prevalence of physical illness among psychiatric in-patients who die of natural causes. Psychiatr Serv. 1998;49:788-93.

11. Bachrach LL. The future of the state hospital. Hosp Community Psychiatry. 1986;37:467-74.

12. Gralnick A. Build a better state hospital: deinstitutionalization has failed. Hosp Community Psychiatry. 1985;36:738-41.

13. Semke J, Fisher WH, Goldman HH, Hirad A. The evolving role of the state hospital in the care and treatment of older adults: state trends, 1984-1993. Psychiatr Serv. 1996;47:1082-7.

14. Saravay SM. Medical and depressive comorbidity in psychiatric patients. Gen Hosp Psychiatry. 1995;17:321-3.

15. Appleby L, Shaw J, Amos T. Sudden unexplained death in psychiatric in-patients. Br J Psychiatry. 2000;176:405-6.

16. Fenton WS, Stover ES. Mood disorders: cardiovascular and diabetes comorbidity. Curr Opin Psychiatry. 2006;19:421-7.

17. Laursen TM. Life expectancy among persons with schizophrenia or treat common general medical illness and coordinate with other colleagues, namely from emergency and internal medicine, neurology and endocrinology. A comprehensive evaluation at the Emergency Department is mandatory, in order to adequately screen for delirium and other general medical illnesses that may mimic psychiatric presentations or that may be presented alongside, as comorbid conditions. Therefore, collaborative strategy is the most effective means to reach that goal.

\section{PROTECTION OF HUMANS AND ANIMALS}

The authors declare that the procedures were followed according to the regulations established by the Clinical Research and Ethics Committee and to the Helsinki Declaration of the World Medical Association.

\section{DATA CONFIDENTIALITY}

The authors declare having followed the protocols in use at their working center regarding patient's data publication.

\section{CONFLICTS OF INTEREST}

The authors declare that there are no conflicts of interest.

\section{FUNDING SOURCES}

No subsidies or grants contributed to this work.

bipolar affective disorder. Schizophr Res. 2011;131:101-4

18. Leucht S, Burkard T, Henderson J, Maj M, Sartorius N. Physical illness and schizophrenia: a review of the literature. Acta Psychiatr Scand. 2007; $116: 317-33$

19. Lwin A, Symeon C, Jan F, Sule A. Morbidity and mortality in schizophrenia. Br J Hosp Med. 2011;72: 628-30.

20. Mitchell AJ, Malone D. Physical health and schizophrenia. Curr Opin Psychiatry. 2006;19:432-7.

21. Saha S, Chant D, McGrath J. A systematic review of mortality in schizophrenia. Arch Gen Psychiatry. 2007;64:1123-31.

22. Tsuang MT, Perkins K, Simpson JC. Physical diseases in schizophrenia and affective disorder. J Clin Psychiatry. 1983;44:42-6.

23. Harris AE. Physical disease and schizophrenia. Schizophr Bull. 1988;14:85-96.

24. Driscoli JS, Melnick NR, Quinn FR, Lomax N, Davignon JP, Ing R, et al. Psychotropic drugs as potential antitumor agents: a selective screening study. Cancer Treat Rep. 1978;62:45-74.

25. Mortensen PB. The incidence of cancer in schizophrenic patients. J Epidemiol Community Health. 1989;43:43-7.

26. Grinshpoon A, Barchana M, Ponizovsky A, Lipshitz I, Nahon D, Tal O, et al. Cancer in schizophrenia: is the risk higher or lower? Schizophr Res. 2005;73:333-41.

27. Goldacre MJ, Kurina LM, Wotton CJ, Yeates D, Seagroat V. Schizophrenia and cancer: an epidemiological study. Br J Psychiatry. 2005;187:334-8.

28. Stubbs B, Thompson T, Acaster S, Vancampfort D, Gaughran F, Correll CU. Decreased pain sensitivity among people with schizophrenia: a meta-analysis of experimental pain induction studies. Pain. 2015;156:2121-31.

29. Shinde SS, Nagarajaiah, Narayanaswamy JC, Viswanath B, Kumar NC, Gangadhar BN, et al. Mortality among inpatients of a psychiatric hospital: Indian perspective. Indian J Psychol Med. 2014;36:142-6.

30. Sims AC. Mortality statistics in psychiatry. Br J Psychiatry. 2001;179: 477-8.

31. Graça J, Klut C, Trancas B, Borja-Santos N, Cardoso G. Characteristics of frequent users of an acute psychiatric inpatient unit: a five-year study in Portugal. Psychiatr Serv. 2013;64:192-5.

32. Alexandre J, Ribeiro R, Cardoso G. Ethnic and clinical characteristics 
of a Portuguese psychiatric inpatient population. Transcult Psychiatry. 2010;47: 314-21.

33. Lei $n{ }^{\circ} 36 / 98$ de 24 de Julho. Diário da Républica nº 169-24-7-1998-I Série-A.

34. Bento A, Pires T, Silva NR, Bacelar F, Malheiro C. A mortalidade dos doentes psiquiátricos do Montijo e de Alcochete (1988-1991). Rev Psiquiatr. 1992;5:79-83.

35. Tidemalm D, Waern M, Stefansson C, Elofsson S, Runeson B. Excess mortality in persons with severe mental disorder in Sweden: a cohort study of 12103 individuals with and without contact with psychiatric services. Clin Pract Epidemiol Ment Health. 2008;4:23.

36. Wheeler A, Robinson E, Robinson G. Admissions to acute psychiatric inpatient services in Auckland, New Zealand: a demographic and diagnostic review. N Z Med J. 2005;118:U1752.

37. Harris EC, Barraclough B. Excess mortality of mental disorder. $\mathrm{Br} \mathrm{J}$ Psychiatry. 1998;173:11-53.

38. Joukamaa M, Heliovaara M, Knekt P, Aromaa A, Raitasalo R, Lehtinen V. Mental disorders and cause-specific mortality. $\mathrm{Br} \mathrm{J}$ Psychiatry. 2001;179:498-502.

39. Hunt IM, Bickeley H, Windfuhr K, Shaw J, Appleby L, Kapur N. Suicide in recently admitted psychiatric in-patients: a case-control study. J Affect Disord. 2013;144:123-8.

40. Hoyer EH, Mortensen PB, Olesen AV. Mortality and causes of death in a total national sample of patients with affective disorders admitted for the first time between 1973 and 1993. Br J Psychiatry. 2000;176:76-82.

41. Lawrence D, Jablensky AV, Holman CD, Pinder TJ. Mortality in Western Australian psychiatric patients. Soc Psychiatry Psychiatr Epidemiol. 2000;35:341-7.

42. Miller BJ, Paschall CB, Svendsen DP. Mortality and medical comorbidity among patients with serious mental illness. Psychiatr Serv. 2006;57:1482-7.

43. Rasanen S, Hakko H, Viilo K, Meyer-Rochow VB, Moring J. Excess mortality among long-stay psychiatric patients in Northern Finland. Soc Psychiatry Psychiatr Epidemiol. 2003;38:297-304.

44. Licht RW, Mortensen PB, Gouliaev G, Lund J. Mortality in Danish psychiatric long stay patients. Acta Psychiatrica Scandinavica. 1993;87:336-41.

45. Ifteni P, Correll CU, Burtea V, Kane JM, Manu P. Sudden unexpected death in schizophrenia: autopsy findings in psychiatric inpatients. Schizophr Res. 2014;155:72-6.

46. Shulman M, Jennifer $\mathrm{NI}$, Manu P. Thrombotic complications of treatment with antipsychotic drugs. Minerva Med. 2013;104:175-84

47. Bazemore $\mathrm{PH}$, Tonkonogy J, Ananth R. Dysphagia in psychiatric patients: clinical and videofluoroscopic study. Dysphagia. 1991;6: 2-5.

48. Fioritti A, Giaccotto L, Melega V. Choking incidents among psychiatric patients: retrospective analysis of thirty-one cases from west Bologna psychiatric wards. Can J Psychiatry. 1997;42:515-20.

49. Trigoboff E, Grace J, Szymanski H, Bhullar J, Lee C, Watson T. Sialorrhea and aspiration pneumonia: a case study. Innov Clin Neurosci. 2013;10:20-7.

50. Hinkes R, Quesada T, Currier M, Gonzalez-Blanco M. Aspiration pneumonia possibly secondary to clozapine-induced sialorrhea. [Letter] J Clin Psychopharmacol. 1996;16:462-3.

51. American Diabetes Association; American Psychiatric Association; American Association of Clinical Endocrinologists; North American Association for the Study of Obesity. Consensus development conference on antipsychotic drugs and obesity and diabetes. J Clin Psychiatry. 2004;65:267-72. 